\title{
Fellowships and subspecialization in anesthesia: Are they good, bad, or both?
}

\author{
Thomas C. Mutter, MD
}

Received: 2 February 2016/Accepted: 8 March 2016/Published online: 5 April 2016

(C) Canadian Anesthesiologists' Society 2016

\section{To the Editor,}

The interesting survey of Canadian anesthesia residents by Khan et al. ${ }^{1}$ and the accompanying editorial by O'Leary and Murphy ${ }^{2}$ may have overlooked some important and arguably contentious issues in their idealistic portrayals of fellowships and subspecialization in anesthesiology.

Prospective Canadian fellows "investing" in their career are currently doing so in a fellowship market that is largely unregulated by a national body. As a result, it is entirely possible that what fellows invest in their fellowship and the quality of the experience they receive in return vary greatly among institutions. Of equal importance is the potential conflict of interest wherein departments and mentors ${ }^{3,4}$ advising residents to pursue fellowships may benefit indirectly from the financial resources and academic time generated by these fellows.

After completing a fellowship, most anesthesia subspecialists continue to practice regularly outside their subspecialty, especially while on call after-hours. In this context, could a narrow scope of clinical practice (or no clinical practice at all), during a fellowship completed immediately after residency, have a negative affect on a fellow's subsequent ability to develop a confident, broadbased consultant practice? Even when established in

This letter is accompanied by a reply. Please see Can J Anesth 2016; 63: this issue.

T. C. Mutter, MD ( $\square)$

Department of Anesthesia and Perioperative Medicine,

University of Manitoba, Winnipeg, MB, Canada

e-mail: tmutter@exchange.hsc.mb.ca practice, it could still be difficult to maintain a balance of minimal competence in the broader specialty while excelling in the subspecialty. An interesting follow-up to the work of Khan et al. ${ }^{1}$ would be to survey recent fellowship graduates regarding all of the above issues. Their perspectives might be more informative than those of the relatively junior residents in the survey, ${ }^{1}$ who likely had limited exposure to both clinical and nonclinical subspecialities.

Ultimately, regardless of any subspecialty training, all departments need, as their backbone, individuals with a strong commitment to excellent clinical care and continued quality improvement. Academic departments also need leaders in research, education, and administration. These skills, however, are not a guaranteed outcome of subspecialization, and formal fellowship training is not the only way to acquire them. Historically, when fellowships were rarer, they likely attracted individuals with academic aspirations and abilities because they provided a relatively unique, tangible credential. Now, as intimated in both the survey ${ }^{1}$ and the accompanying editorial, ${ }^{2}$ fellowships are much more common and a de facto requirement for a clinical appointment at most major Canadian centres. They are less likely to represent an exceptional commitment to the specialty or the foundation of an academic "career" and more likely to simply be the last step in getting a "job." 2

Some subspecialization is clearly necessary for academic and subspecialty clinical excellence, but it should occur in the right way and for the right reasons. This means first benefitting our patients, but also considering the needs of our trainees, our academic departments, and the specialty as a whole. Addressing these complex issues requires a detailed discussion, and I thank the Journal and its contributors for starting it. 
Conflicts of interest None declared.

Editorial responsibility This submission was handled by Dr. Steven Backman, Associate Editor, Canadian Journal of Anesthesia.

\section{References}

1. Khan J, Gilbert J, Sharma A, LeManach Y, Yee D. Perspectives of anesthesia residents training in Canada on fellowship training, research, and future practice location. Can J Anesth 2015; 62: 956-63.

2. O'Leary S, Murphy M. Anesthesiology: Is it a career, a job, or both? Can J Anesth 2015; 62: 943-5.

3. Miller DR, McCartney CJ. Mentoring during anesthesia residency training: challenges and opportunities. Can J Anesth 2015; 62: 950-5.

4. Zakus $P$, Gelb AW, Flexman AM. A survey of mentorship among Canadian anesthesiology residents. Can J Anesth 2015; 62: 972-8. 